\title{
Morphological Studies in Novel Liquid Rubber Modified Epoxies
}

\author{
Dheeraj Gunwant*, M. G. H. Zaidi**, P. L. Sah* \\ *(Department of Mechanical Engineering, G. B. Pant University of Ag. \& Tech., Pantnagar, Udham Singh \\ Nagar, Uttarakhand-263145) \\ ** (Department of Chemistry, G. B. Pant University of Ag. \& Tech., Pantnagar, Udham Singh Nagar, \\ Uttarakhand-263145)
}

\begin{abstract}
The aim of this article is to present morphological studies on the tensile fractured specimens of novel liquid rubber obtained from the pyrolysis of scrap rubber. Such a study is crucial for gaining useful insight into the toughening mechanisms existing in rubber modified systems. A DGEBA based epoxy resin was first modified with varying concentrations (0-15 wt. \%) of the liquid rubber. Dogbone shaped specimens of the cast plaques of the modified epoxies were tested under uniaxial tensile loading. The fracture surface was elucidated with the help of scanning electron microscopy (SEM). It was observed that biphasic morphology characterized with continuous epoxy phase and microvoids distributed throughout the epoxy domain develop in the modified epoxies. Cavitation of rubber particles under crack tip stresses is the reason behind development of these microvoids. The diameter of these microvoids were analyzed using the image analysis technique and was observed to increase with the concentration of rubber. Prevalent toughening mechanisms were visualized in the SEM micrographs necessary for the development of tougher and more ductile rubber modified epoxy systems.
\end{abstract}

Keywords: Cavitation, Rubber toughened epoxy, Scanning Electron Microscopy

\section{INTRODUCTION}

Since their introduction in 1947, epoxy resins have found wide acceptance in various application areas ranging from floor coatings to high performance composites. Such a broad spectrum of applicability is obtained by the proper selection of the resin-curing agent combination and controlled curing conditions. Although, cured epoxies possess right combination of strength and stiffness properties and thermal stability, yet, they are brittle due to limited energy absorbing capability and poor crack resistance. Therefore, it becomes of paramount importance that their brittleness is mitigated in order to enhance their applications to high toughness requiring fields. Addition of a softer rubbery phase into epoxy resin has been accepted as a viable route for alleviating this problem. Rubber toughening of epoxies is an interesting field which leads to the formation of distinct phase separated morphology following reaction induced phase separation in the rubber-epoxy blends. This phase separation is a result of rise in molecular weight of the epoxy resin as curing proceeds [1]. This leads to the reduction in the miscibility of rubber phase in epoxy and formation of micrometer scaled rubber 'particles'. These rubber particles undergo cavitation under crack tip stresses and facilitate the yielding of matrix in their vicinity [2]. The voids that form due to the cavitation of rubber particles act as further stressraisers. In addition to shear yielding, other mechanisms viz. micro-cracking, crack deflection, crack bifurcation, crack pinning, crack bridging, or multiple fracture may also exist in the rubber-epoxy blends [3]. Numerous efforts have been made to blend a host of liquid rubbers with commercially available DGEBA based epoxy resins to enhance the toughness of the epoxies. Out of them, notable contributions have been made by [4] who used amine terminated butadiene acrylonitrile rubber (ATBN). They noticed a phase separated morphology using SEM, characterized by microvoids distributed in the epoxy matrix. Noticeable enhancement in notched and un-notched impact strengths, percentage elongation and fracture toughness were observed by them. Blends of CTBN rubber and epoxy resins were developed by [5]. They noticed a reduction in the tensile strength and modulus of the cured blends with rubber concentration. The ductility however, marked by percentage elongation at break and fracture toughness increased in the cured blends. Clear evidence of cavitation of CTBN particles characterized by microvoid formation were visualized by them through SEM. Efforts have also been made to blend other liquid rubbers such as hydroxy terminated polybutadiene (HTPB) [6], liquid natural rubber (LNR) [7], liquid epoxidized natural rubber (LENR) [8], epoxy terminated polybutadiene (ETPB), [9] and poly (vinyl butyral) (PVB) [10]. All of them observed biphasic morphology in the rubber modified epoxy systems. Such morphology forms the backbone of epoxy toughening mechanisms and is imperative for 
effective toughening to be obtained. The search for low cost alternatives of the above mentioned liquid rubbers is an interminable process. Keeping in view such a need, in the present investigation, effort has been made to modify a commercially available DGEBA based epoxy resin with a cost-effective liquid rubber (LR) obtained from the pyrolysis of waste rubber. Dogbone shaped samples of the cured LR-epoxy blends were tested for tensile properties. Morphology of the LR-epoxy blends was revealed through the fractographic analysis of fractured surface using Field Emission Scanning Electron Microscopy (FESEM). The micrographs were critically evaluated and various toughening mechanisms were visualized in them.

\section{EXPERIMENTAL}

\subsection{Materials}

DGEBA based epoxy resin (CY-230) and TETA (HY-951) were purchased from M/S Huntsman India Limited. Liquid filler material LR was procured from locally available rubber recycling plant. The composition of LR was deduced through micro-analysis and found as: $(\mathrm{C}-28.4 \%, \mathrm{H}-2.42 \%$, $\mathrm{N}-0.42 \%, \mathrm{~S}-0.36 \%)$. Its density was obtained to be $1.1 \mathrm{~g} / \mathrm{cc}$. The moulds for fabrication of casting with required dimensions were fabricated from GI sheets for development of castings. Rest of the chemicals and solvents (purity $\geq 98 \%$ ) were locally procured and used without further purification.

\subsection{Preparation of LREs}

A series of compositions of LR with epoxy (0-15 wt. \%) were prepared at room temperature through mechanical mixing at $500 \mathrm{rpm}$ to obtain homogenous solution. The solution was heated at 80 ${ }^{\circ} \mathrm{C}$ for about 45 minutes followed by degassing at $10 \mathrm{mmHg}$ to remove any entrapped air. It was subsequently cooled to room temperature and cured with 10 wt. \% curing agent. The obtained solution was subsequently cast into GI moulds coated with a fine coating of release agent. A two-step curing schedule was followed. It was first cured for $16 \mathrm{~h}$ at $25{ }^{\circ} \mathrm{C}$ followed by post curing for $2 \mathrm{~h}$ at $60{ }^{\circ} \mathrm{C}$ to ensure proper cross-linking and development of phase separated morphology [11]. The LREs were designated as per the following scheme.

Table 1: Designation of LREs

\begin{tabular}{|c|c|c|}
\hline $\begin{array}{c}\text { S. } \\
\text { No. }\end{array}$ & $\begin{array}{c}\text { LR concentration } \\
\text { (wt. \%) }\end{array}$ & $\begin{array}{c}\text { LRE } \\
\text { designation }\end{array}$ \\
\hline 1 & 0 & LRE0 \\
\hline 2 & 5 & LRE5 \\
\hline 3 & 10 & LRE10 \\
\hline 4 & 15 & LRE15 \\
\hline
\end{tabular}

2.2 Field Emission Scanning Electron Microscopy (FESEM) The morphology of gold coated fractured specimen was elucidated with the help of FESEM analysis over a Carl Zeiss ULTRA PLUS microscope. The electron voltage of was maintained at 15 and $20 \mathrm{kV}$.

\section{RESULTS AND DISCUSSION}

Gold coated fracture surface of tensile test specimens were examined using FESEM. No stress whitening zones are visible in neat epoxy as it is a single phase material. There is a clear absence of plastic deformation in its topography, marking the inherent brittle nature of cured epoxy and lack of toughness. Such brittle failure in the unmodified (LR0) epoxy polymer is more evident at the higher magnification micrograph in fig. 1 . On the other hand, as the crack progresses in the LR modified epoxy, stress-whitening occurs ahead of the crack tip. This stress-whitening is proportional to the energy absorbed during the propagation of crack. The size of this stress-whitened zone was found to increase with the LR concentration. The stresswhitening effect occurs mainly due to the scattering of visible light from a layer of scattering centers, such as the microvoids.

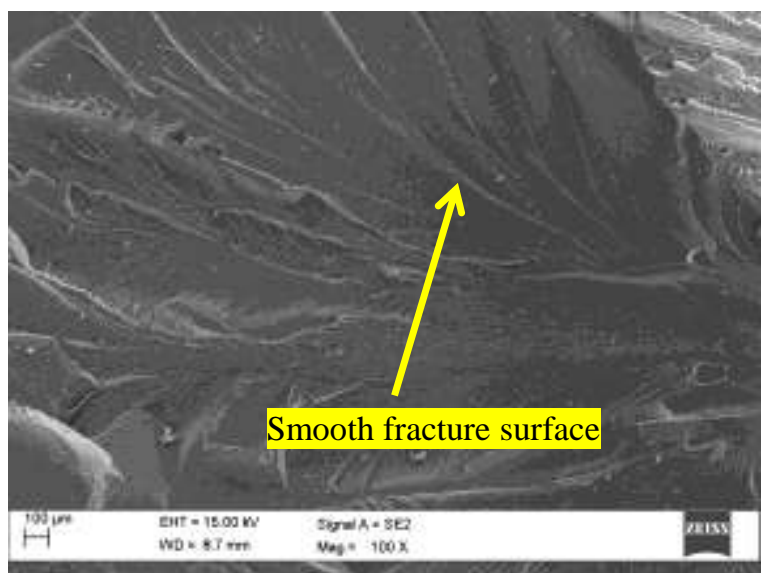

Figure 1. SEM image of neat epoxy at $100 \mathrm{X}, 100 \mu \mathrm{m}$

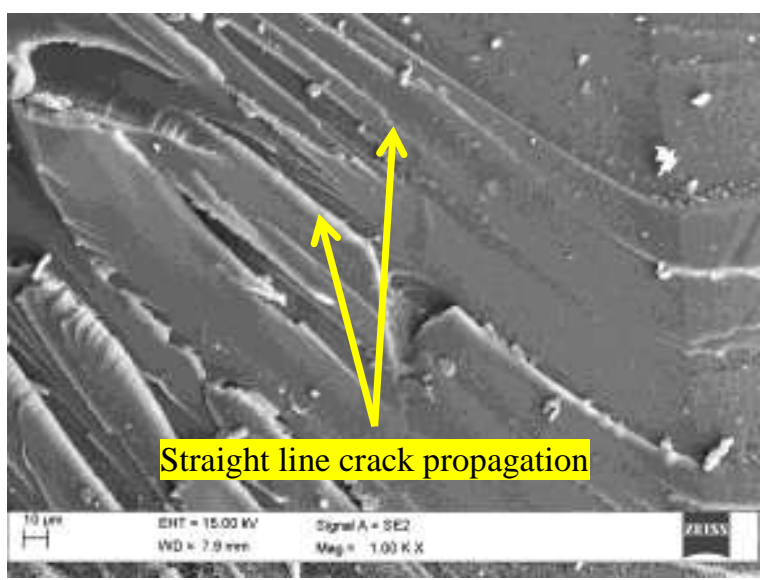

Figure 2. SEM image of neat epoxy at $1000 \mathrm{X}, 10 \mu \mathrm{m}$ SEM micrograph of LR modified epoxies show that the rubber particles formed due to the 
phase separation process have cavitated and microvoid formation has taken place due to loading. SEM images of LR modified epoxies as function of LR concentration is shown in fig. (3-7). As the LR concentration is increased, the size of microvoids formed post-cavitation increases (see fig. 4). Their density also increases with LR concentration. Simultaneously, there diameters become more and more uniform. These features may be the result of increasing uniformity in the rubber particle size and enhanced interaction between particles with increase in the LR content. The mechanism of crack arrest can also be seen in the image. Crack arrest leads to enhanced energy absorption leading to an increase in the fracture energy of LR-epoxy blends.

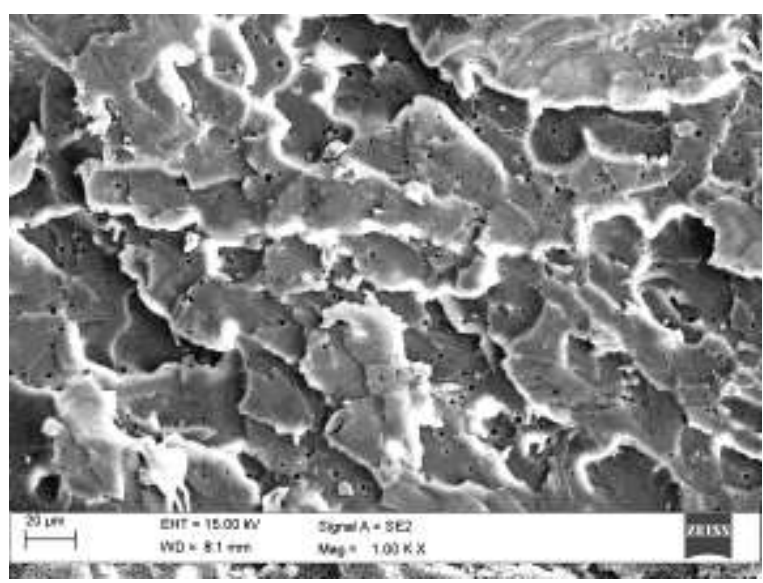

Figure 3. SEM image of LRE5 at 1000X, $20 \mu \mathrm{m}$

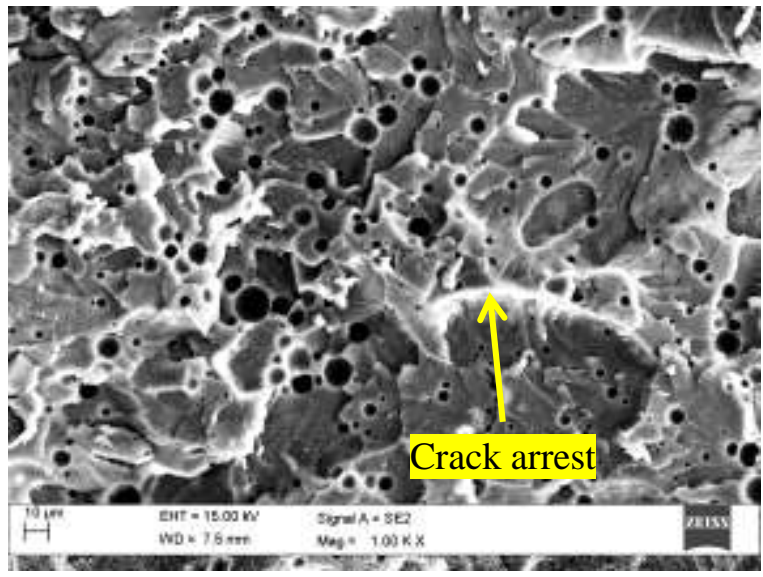

Figure 4. SEM image of LRE10 at $1000 \mathrm{X}, 10 \mu \mathrm{m}$

To present a clearer evidence of the cavitation phenomenon taking place in the LR modified epoxy, a higher magnification (5000X, $2 \mu \mathrm{m})$ of LRE10 is shown in fig. 5 . The formation of void post-cavitation is visible in the morphology. Some uncavitated rubber particles are also visible in the micrograph. These rubber particles might have been located in the region of fast fracture region, due to which they were unable to cavitate under the crack-tip stresses. The cavitation of these rubber particles is known to increase the size of microvoids by 50 to $200 \%$ of their original size. This increase in microvoid diameter in the tensile test specimens is mainly due to the hydrostatic stress experienced by the rubber particles due to the stress triaxiality associated with the crack tip. This hydrostatic stress is the reason behind the subsequent void formation as evident in fig. 5 .

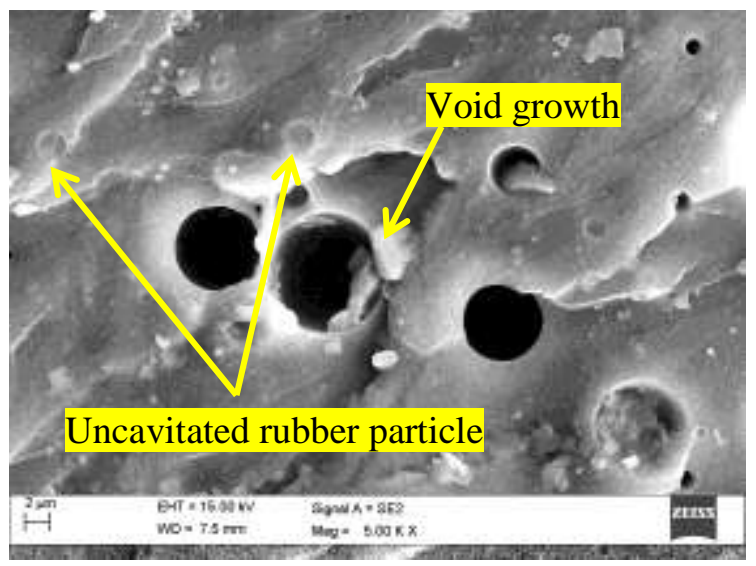

Figure 5. SEM image of LRE10 at 5000X, $2 \mu \mathrm{m}$

SEM image of LRE15 is shown in fig.5. The stresswhitened zones around microvoids are enhanced as the LR concentration is increased.

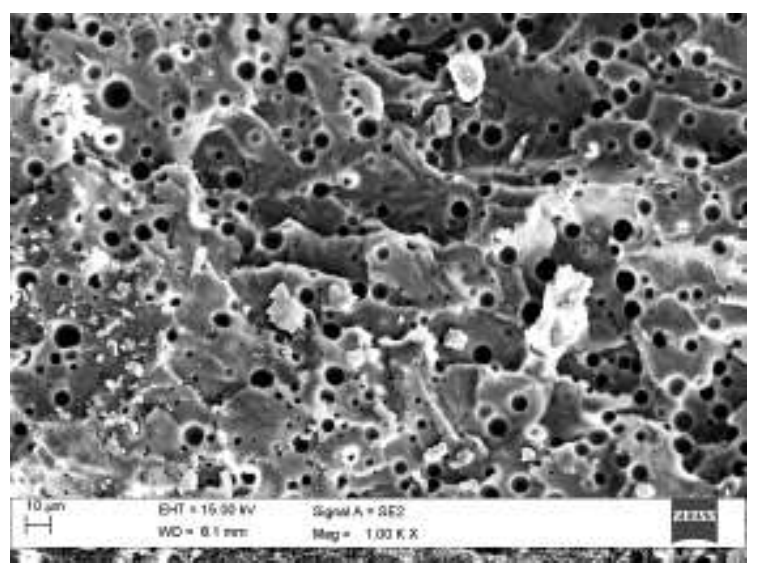

Figure 6. SEM image of LRE10 at 5000X, $2 \mu \mathrm{m}$

A higher magnification image of LRE15 is shown in the fig. 7. The formation of phase separated rubber particles is clearly evident in the SEM micrograph. 


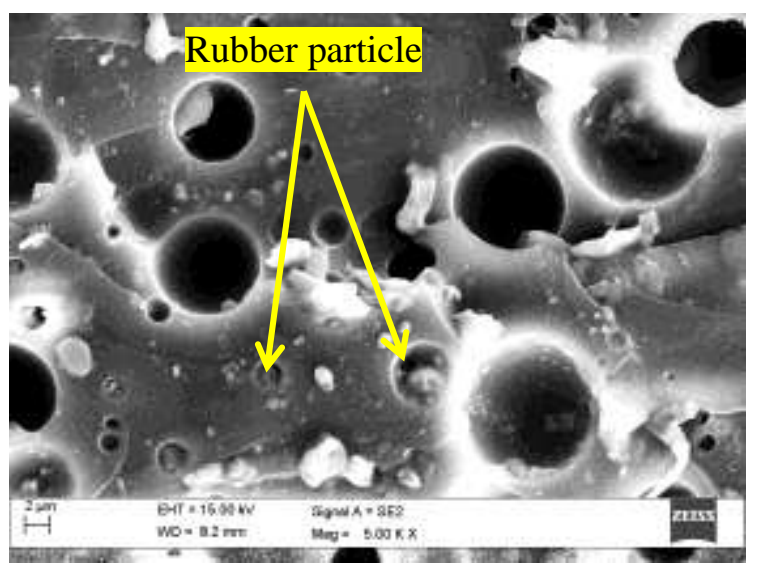

Figure 7. SEM image of LRE10 at 5000X, $2 \mu \mathrm{m}$

The size of these microvoids was analyzed with the help of image analysis technique and results for same are presented in fig. 8 .

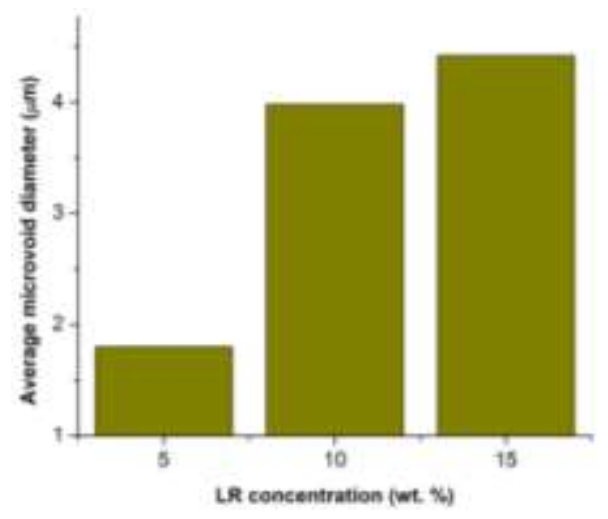

Figure 8. Variation of average microvoid diameter with LR concentration

As shown in fig. 7 the diameter of microvoids formed post-cavitation of rubber particles increases with the concentration of LR. For LRE5, the average diameter of microvoids is $1.82 \mu \mathrm{m}$. This value increases to $3.98 \mu \mathrm{m}$ for LRE10. A further increase in LR concentration, i.e. for LRE15, the microvoid diameter attained a value of $4.42 \mu \mathrm{m}$.

\section{CONCLUSION}

In the present investigation, a DGEBA based epoxy resin was modified with varying concentrations of a novel liquid rubber (LR) obtained from the pyrolysis of scrap rubber. Tensile tests were conducted on the cured samples of LREs. Fractured surfaces were analyzed through scanning electron microscopy technique to elucidate the morphology present in them. Multiple deformation mechanisms were found to exist in the LREs. Out of the myriad of deformation mechanisms, it was found that, phase separated rubber particles cavitated and fractured under loading and led to the formation of microvoids uniformly distributed throughout the epoxy domain. Presence of these rubber particles and their subsequent cavitation and void growth facilitated the shear yielding of the inherently brittle epoxy matrix. The evidence of shear yielding was manifested in the stress-whitening effect ostensible in the micrographs. The complicated task of void formation in a solid has apparently been accomplished due to the presence of the phase separated rubber particles. These voids grow and dissipate bulk strain energy. They also act as stress-raisers, and ultimately cause shear banding to occur. Large plastic zones are formed ahead of the crack tip enabling absorption of energy. The fracture toughness any material depends on the ease with which the matrix can undergo shear deformation and this energy absorbing capability.

\section{REFERENCES}

[1]. D. Verchere, H. Sautereau, J. P. Pascault, S. M. Moschiar, C. C. Riccardi, and R. J. J. William, Rubber-modified epoxies. I. Influence of carboxyl-terminated butadiene-acrylonitrile random copolymers (CTBN) on the polymerization and phase separation processes, Journal of Applied Polymer Science, 41(3-4), 1990, 467-485.

[2]. D. Ratna, and A. K. Banthia, Rubber toughened epoxy, Macromolecular research, 12(1), 2004, 11-21.

[3]. H. Kargarzadeh, I. Ahmad, I. Abdullah, R. Thomas, A. Dufresne, S. Thomas and A. Hassan, Functionalized liquid natural rubber and liquid epoxidized natural rubber: A promising green toughening agent for polyester, Journal of Applied Polymer Science, 132(3), 2015.

[4]. N. Chikhi, S. Fellahi, and M. Bakar, Modification of epoxy resin using reactive liquid (ATBN) rubber. European Polymer Journal, 38(2), 2002, 251-264.

[5]. S. K. Shukla, and D. Srivastava, Blends of modified epoxy resin and carboxyl-

terminated polybutadiene. I. Journal of applied polymer science,100(3), 2006, 1802-1808.

[6]. R. Thomas, D. Yumei, H. Yuelong, Y. Le, P. Moldenaers, Y. Weimin, T. Czigany and S. Thomas Miscibility, morphology, thermal, and mechanical properties of a DGEBA based epoxy resin toughened with a liquid rubber. Polymer, 49(1), 2008, 278294.

[7]. Y. S. Lee, S. H. Ahmad, R. Rasid S. Y. E. Noum, C. H. Yew, and A. T. Mou'ad, Effects of liquid natural rubber (LNR) on the mechanical properties of LNR toughened epoxy composite, Sains Malaysiana, 40(7), 2011, 679-683.

[8]. S. K. Tan, S. Ahmad, C. H. Chia, A. Mamun and H. P. Heim, A comparison 
study of liquid natural rubber (LNR) and liquid epoxidized natural rubber (LENR) as the toughening agent for epoxy, American Journal of Materials Science, 3(3), 2013, 55-61.

[9]. H. Yahyaie, M. Ebrahimi, H. V. Tahami, and E. R. Mafi, Toughening mechanisms of rubber modified thin film epoxy resins, Progress in Organic Coatings, 76(1), 2013, 286-292.

[10]. B. Yang, W. Wang, and J. Huang, Synergic effects of poly (vinyl butyral) on toughening epoxies by nanostructured rubbers, Polymer, 77, 2015, 129-142.

[11]. K. P. Unnikrishnan, and E. T. Thachil, Toughening of epoxy resins, Designed monomers and polymers, 9(2), 2006, 129152.nz 